\title{
Brucelosis en un escolar
}

\author{
Alejandra Reyes J. y Julia Villarroel B.
}

\section{Brucellosis in a student}

We describe the case of a student with a history of two and a half months of fever, hepatosplenomegaly, cutaneous, hematological and bone manifestations, within an epidemiological background compatible with the diagnosis of Brucellosis. Diagnosis of Brucella abortus was confirmed by serology and positive blood cultures. Clinical manifestations of brucellosis and diagnostic and treatment strategies are reviewed.

Key words: Brucellosis; Human disease.

Palabras claves: Brucelosis; Enfermedad en el Hombre.

\section{Introducción}

$\mathrm{L}$ a brucelosis es una zoonosis de distribución mundial producida por Brucella sp, siendo endémica en el área Mediterránea, Oriente Medio, Península arábica y Latinoamérica. En América, hay áreas con alta incidencia como por ejemplo: México, Perú y la Cuenca del Río de la Plata ${ }^{1}$.

La enfermedad en el Hombre se ha asociado al contacto directo con el ganado, propio de algunas profesiones como veterinarios, ganaderos y pastores, pero también con el consumo de alimentos lácteos no controlados. La transmisión de la enfermedad de persona a persona es infrecuente, y en la literatura se han comunicado algunos casos de transmisión transplacentaria ${ }^{2}$.

En Chile, el Servicio Agrícola Ganadero (SAG) estableció el control de la brucelosis bovina en 1975 y la infección humana es de notificación obligatoria, pero las estadísticas oficiales no reflejan la verdadera incidencia de esta enfermedad, estimándose que sería 10 a 25 veces más alta que la notificada. En nuestro país se declaró erradicada la especie propia del ganado caprino (B. melitensis) en 1987; sin embargo, se producen casos por $B$. abortus en el ganado bovino y en humanos, aunque con baja incidencia, afectando principalmente a las regiones $\mathrm{VIII}^{\circ}, \mathrm{X}^{\mathrm{o}}$ y Región Metropolitana. Las tasas disminuyeron desde 0,21 por 100.000 habitantes a 0,06 por 100.000 habitantes en el año 2003 . Durante el año 2004 se notificaron 7 casos de brucelosis humana en nuestro país. No se han registrado muertes por esta causa desde el año $1990^{3}$.

El género Brucella comprende tradicionalmente 6 especies: B. melitensis, B. abortus, B. suis, B. neotomae, $B$. ovis y $B$. canis; de éstas, sólo las cuatro primeras son patógenas para el hombre, siendo B. melitensis la más frecuente en el mundo ${ }^{4-5}$. Se han aislado dos nuevas especies de Brucella en huéspedes marinos, provisoriamente llamadas B. pinnipediae y $B$. cetaceae.

$\mathrm{La}$ brucelosis da origen a manifestaciones de gran polimorfismo, por lo cual, debe ser incluida en el diagnóstico diferencial de una variedad de cuadros clínicos. Característicamente, en el niño la evolución es más corta, con sintomatología inespecífica y generalmente existe el antecedente de exposición a animales o alimentos contaminados.

Por la baja frecuencia de esta patología en nuestro país, hemos considerado interesante dar a conocer el caso de un escolar estudiado en nuestro servicio y oportunamente notificado ${ }^{3}$.

\section{Caso clínico}

Varón de 11 años de edad, portador de una epilepsia rolándica, en tratamiento con ácido valproico. Sin antecedentes de ruralidad ni contacto con animales. Presentaba al momento de su ingreso un cuadro de dos meses y medio de evolución, caracterizado por fiebre hasta $40{ }^{\circ} \mathrm{C}$, artralgias de ambas rodillas y hombros, cefalea holocranea y compromiso del estado general. Al examen físico destacaba la presencia de hígado palpable $5 \mathrm{~cm}$ bajo el reborde costal, sudoración, adenopatías en las cadenas cervicales laterales y soplo sistólico de 2-3/6 en el foco aórtico. De los exámenes realizados en forma ambulatoria, cabe mencionar: 6 hemocultivos (-)s, PCR de $83 \mathrm{mg} / \mathrm{l}$, serología para virus de Epstein Barr (IgM) dudosamente positiva, ecografía y TAC de abdomen con adenopatías retroperitoneales y hepatoesplenomegalia.

\author{
Hospital Félix Bulnes Cerda \\ Santiago, Chile \\ Servicio de Pediatría \\ Unidad de Infecciosos. \\ Recibido: 5 diciembre 2005 \\ Aceptado: 4 julio 2006 \\ Correspondencia a: \\ Alejandra Reyes Jiménez \\ infecciosofelix@yahoo.es.
}


Se hospitalizó en la Unidad de Infecciosos con los diagnósticos de síndrome febril de evolución prolongada: ¿endocarditis infecciosa?, ¿mesenquimopatía (artritis reumatoidea juvenil)?, ¿mononucleosis infecciosa?

Evolucionó febril, con episodios de alzas térmicas acompañadas de mialgias, cianosis distal y sudoración profusa. Posteriormente, se agregaron artralgia de la cadera derecha y lesiones máculo-papulares en el tronco y las extremidades inferiores, de las cuales, la biopsia demostró una dermatitis intersticial y perivascular eosinofílica. La hepatomegalia se redujo a $3 \mathrm{~cm}$, sumándose una esplenomegalia de 1 a $2 \mathrm{~cm}$ bajo el reborde costal.

Al mes de hospitalización presentó una gingivoestomatitis extensa, que le dificultaba la alimentación, y una lesión eczematosa de 4 por $4 \mathrm{~cm}$, en el brazo izquierdo, que cedió espontáneamente, al cabo de 10 días.

El hemograma de ingreso mostró un recuento normal de leucocitos con una discreta desviación a izquierda, leve anemia normocítica, normocrómica, y recuento plaquetario en valores normales. Coincidiendo con el cuadro de gingivoestomatitis, evolucionó con neutropenia, llegando a tener un recuento absoluto de neutrófilos (RAN) de 357céls $/ \mathrm{mm}^{3}$, manteniéndose con RAN menor de 1.000 céls $/ \mathrm{mm}^{3}$ durante todo el período de hospitalización. La VHS y la PCR se encontraron dentro de rangos normales. Se le realizaron dos ecocardiografias doppler convencionales y una transesofágica, siendo descartado el diagnóstico de endocarditis infecciosa. Fue evaluado por Reumatología, planteándose el diagnóstico de una probable panarterirtis nodosa. El estudio inmunológico no arrojó alteraciones significativas e incluyó: inmunoglobulinas $\operatorname{IgA}, \operatorname{IgG}$, IgM, IgE, subclases de inmunoglobulinas $\mathrm{G}$, $\%$ natural killer, fagocitosis, actividad hemolítica, subpoblaciones linfocitarias, $\mathrm{CH}_{50}, \mathrm{C} 3, \mathrm{C} 4, \mathrm{CD} 4$ y CD8. Los anticuerpos antinucleares y células del lupus fueron negativos. El estudio serológico (IgM para citomegalovirus, IgG para Bartonella haenselae, IgM para virus de Epstein Barr, IgM para parvovirus B19, IgM para Mycoplasma pneumoniae, IgM para virus de hepatitis A) fue negativo, al igual que la serología (IFI) para Toxoplasma gondii y el análisis del citoquímico y cultivo de LCR. El antígeno de superficie para hepatitis B, ELISA para VIH, VDRL, fondo de ojo y TAC cerebral fueron normales.

Coincidiendo con la gingivostomatitis, neutropenia y antiestreptolisina (ASO) de $400 \mathrm{UI} / \mathrm{ml}$ se aisló en tres hemocultivos un Streptococcus $\alpha$ hemolítico. La cepa fue enviada para estudio al ISP identificándose posteriormente como Streptococcus mitis. Se suspendió el ácido valproico iniciándose tratamiento con penicilina $\mathrm{G}$ y luego vancomicina por persistencia de hemo- cultivos $(+)$ s a esta misma bacteria, lo cual, se asoció a una mala evolución clínica. Cursó febril, con compromiso del estado general y se agregó dolor en la pierna derecha, sin signos inflamatorios ni impotencia funcional. El cintigrama óseo mostró una hipercaptación del radiofármaco en la región metafisiaria y submetafisiaria distal de la tibia derecha, por lo cual, ante la evidencia de compromiso óseo, se cambió el tratamiento a clindamicina asociada a rifampicina.

Reevaluando el cuadro clínico, con una evolución de 3 meses y medio, hasta ese momento, lo que no se explicaban exclusivamente por la infección estreptocóccica, se solicitó evaluación hematológica, descartándose una enfermedad mieloproliferativa, a través de un mielograma normal.

A la luz de nuevos antecedentes epidemiológicos que precisaban la ingestión reiterada de queso de procedencia clandestina (de una zona rural de la localidad de María Pinto) y la visita a una granja educativa en Lonquén, donde el niño habría ingerido leche no pasteurizada, se repitieron 4 hemocultivos, obteniéndose, finalmente, el desarrollo de B. abortus. La reacción de Wright-Huddleson dio un título de 1/640. Los hemocultivos se hicieron positivos a las 72 horas de incubación, observándose cocobacilos pequeños e irregulares gramnegativos, que fueron enviados al ISP, centro de referencia, para su identificación.

Se trató con doxiciclina y rifampicina durante 6 semanas, y gentamicina asociada a los anteriores durante los primeros 14 días. El paciente se recuperó lentamente de su neutropenia, cayó la fiebre, desapareciendo el dolor en la pierna derecha y el compromiso del estado general. Se repitió el mielograma al mes de tratamiento, con resultado normal.

La reacción de Wright-Huddleson mostró una caída de los títulos, desde el inicio de la terapia específica a $1 / 160 ; 1 / 80 ; 1 / 10$ y $1 / 10$, al mes, 3,8 y 12 meses respectivamente. El test de ELISA fue positivo para IgG y negativo para $\operatorname{IgM}$ a los 10 meses y al año de seguimiento. El cintigrama óseo realizado al mes de finalizado el tratamiento fue normal.

Finalmente, el niño fue dado de alta al año de seguimiento asintomático y en buenas condiciones generales.

La reacción de Wright-Huddleson del grupo familiar fue negativa. La investigación epidemiológica emprendida por el Departamento de Epidemiología del S.S. Metropolitano Occidente concluyó que la granja educativa donde el paciente había tomado leche expendía el producto no pasteurizado. Una visita inspectiva efectuada por el Servicio del Ambiente verificó que este recinto no contaba con la certificación que lo acreditara libre de brucelosis, lo cual fue comunicado al SAG. 
Dado que, al momento de esta visita el niño ya presentaba algunos de los síntomas de la enfermedad, se piensa que en este caso, la fuente más probable de contagio haya sido la ingestión de queso proveniente de una zona rural afectada de brucelosis bovina, comprado por la familia a un comerciante ambulante.

\section{Discusión}

La brucelosis es conocida como fiebre ondulante, fiebre mediterránea o fiebre de Malta, denominaciones que hacen referencia a una de sus características clínicas o a una localización geográfica, respectivamente ${ }^{1}$.

Etiopatogenia. El género Brucella engloba bacilos gramnegativos pequeños, inmóviles y aerobios, de crecimiento lento y difícil, que requieren para desarrollarse de una atmósfera con 5 a $10 \%$ de $\mathrm{C}_{2}$, incubación a $37^{\circ} \mathrm{C}$, medios de cultivos especiales y sistemas bifásicos.

Estos microorganismos son capaces de sobrevivir y multiplicarse dentro de las células del sistema fagocítico mononuclear. El complemento ayuda en la opsonización y fagocitosis, de tal forma, que este patógeno es rápidamente ingerido por los polimorfonucleares (PMN), atraídos hacia el sitio de inoculación. Su sobrevida intracelular determina las características clínicas de la brucelosis, su curso ondulante, su tendencia a las recaídas y a la cronicidad. En su ubicación intracelular, este microorganismo es resistente a la acción de los policationes y sistemas de killing dependientes de oxígeno, de los fagocitos; se multiplica y es transportado a otros órganos como el SNC, corazón, articulaciones, sistema genitourinario, pulmones y piel.

El hospedero responde produciendo anticuerpos dirigidos contra el LPS y otros antígenos de pared; sin embargo, la respuesta inmune celular será el principal mecanismo de defensa. La infección por las especies más virulentas, como B. melitensis y suis, se ha relacionado con la formación de microabscesos en los tejidos, y la infección por B. abortus con granulomas; cabe señalar, que algunos autores opinan, que la presencia o ausencia de granulomas dependería de la respuesta inmune del huésped y no de la especie de Brucella $^{1-5}$.

La enfermedad se transmite por dos mecanismos claramente definidos: por contagio directo, mediante contacto, inoculación o inhalación, o por vía indirec$t a$, a través de la ingestión de productos lácteos contaminados $^{1}$. El período de incubación es variable, va de 7 días a 3 meses, con una media de 2 a 4 semanas.
Manifestaciones clínicas. La brucelosis humana presenta manifestaciones clínicas muy polimorfas, siendo muchas veces asintomática. La forma clínica aguda, típica, se manifiesta como una enfermedad febril de inicio agudo, con sudoración profusa, desproporcionada a la fiebre existente y de predominio nocturno, con mialgias, artralgias y baja de peso $0^{1-4}$. En los niños el cuadro clínico suele ser autolimitado, los síntomas son más inespecíficos y se manifiestan a las 2 a 4 semanas de producida la infección y, generalmente, existe el antecedente de exposición a alimentos contaminados.

La forma crónica, definida como más de un año de evolución, cursa con mialgias, fatiga, artralgias y depresión. Es muy rara en los niños, generalmente se observa en adultos sobre 30 años de edad y se asocia a infección por B. melitensis ${ }^{1}$.

La duración de los síntomas por más de 30 días, previos al diagnóstico, es el factor de riesgo más importante, para desarrollar las formas focales de la enfermedad. 1-7,8. También se han relacionado estas formas, con la presencia de leucopenia y niveles bajos de PCR. Las formas clínicas focales corresponden al $30 \%$ del total de casos de brucelosis, afectándose frecuentemente el sistema músculo esquelético $(70 \%)$. Las localizaciones más frecuentes en los adultos son la sacroileítis y la espondilitis ${ }^{1}$, a diferencia de los niños, donde las articulaciones afectadas corresponden generalmente a rodillas, codos y tobillos, con compromiso monoarticular u oligoarticular. La espondilitis, si bien es rara en los niños, puede presentarse con lesiones destructivas y abscesos paravertebrales, que frecuentemente requieren de manejo quirúrgico. También ha sido propuesta la brucelosis como una causa de artritis reactiva.

La presencia de fiebre, artralgia y lumbalgia es muy sugerente de brucelosis. Las artralgias pueden afectar a grandes articulaciones o columna dorso lumbar; en este último caso, se puede manifestar por dolor referido a las articulaciones sacroilíacas ${ }^{7-8}$. Las complicaciones osteoarticulares han sido relacionadas con la presencia de HLA-B39 ${ }^{10}$.

Entre otras formas focales de la enfermedad se describen las genitourinarias (6-18\%), ya sea, como epididimitis u orquiepididimitis en el hombre; en la mujer se puede presentar como abscesos tubo-ováricos, abscesos pelvianos, salpingitis crónica, cervicitis y alteraciones de los ciclos menstruales ${ }^{11}$. En la mujer embarazada ocasiona abortos $(10 \%)$ y se han descrito casos de infección transplacentaria ${ }^{12}$.

Las complicaciones neurológicas ${ }^{13-14}(5 \%)$ se presentan de tres formas diferentes: como un cuadro meníngeo de corta evolución, con pleocitosis en el LCR entre 20 a 500 céls. $/ \mathrm{ml}$, de predominio mononuclear; el 
cultivo es positivo en 35 a $50 \%$ de los casos y en 75 a $100 \%$ de los pacientes se detectan anticuerpos específicos en el LCR; un segundo grupo muestra una evolución larga, con una presentación clínica insidiosa, originando una enfermedad meningovascular, y el tercer grupo es el resultado de la inflamación meníngea crónica, con una escasa respuesta inflamatoria, pero que deja secuelas irreversibles en el SNC. Es importante considerar que $20 \%$ de los pacientes, con compromiso meningo-encefálico evidencian sintomatología psiquiátrica $\mathrm{y}$, ocasionalmente, el compromiso neurológico sólo se manifiesta por múltiples infartos secundarios a vasculitis cerebral. Se han reportados caso de síndromes desmielinizantes ${ }^{15}$.

La afectación cardiaca es inusual (0-2\%), siendo más frecuente la endocarditis, complicación que en $50 \%$ de los casos afecta a válvulas aórticas sanas. Es un cuadro grave, con una letalidad de $80 \%{ }^{16-17}$.

La complicación gastrointestinal más frecuente es la hepatitis. Se han se han descrito casos de colecistitis, apendicitis, pancreatitis, perforaciones de íleon, adenitis mesentérica, ascitis y granulomas hepáticos ${ }^{18-21}$.

Sobre el pulmón se pueden observar nódulos, adenopatías hiliares, neumonías lobares e incluso empie$\mathrm{ma}^{22,23}$.

El compromiso renal puede estar dado por invasión directa de la bacteria, ocasionando cuadros de nefritis intersticial, o por depósito de complejos inmunes, que frecuentemente se asocia a endocarditis y puede originar una glomerulonefritis membrano proliferativa, que en general, revierte al tratar la brucelosis ${ }^{1}$.

Las manifestaciones cutáneas son inhabituales, se ha descrito su presentación hasta en $4 \%$ de las series publicadas. En la mayoría de los casos $(90 \%)$ se presentan como un exantema maculo-papular o papulonodular, que compromete predominantemente las extremidades y el tronco, no pruriginoso, con elementos purpúricos en $28 \%$ y con características de eritema nodoso en $11 \%$ de los pacientes. Entre los mecanismos patogénicos involucrados en el compromiso de la piel se describe el depósito de complejos inmunes, fenómenos de hipersensibilidad o la invasión directa del microorganismo ${ }^{24-26}$.

Alteraciones hematológicas ${ }^{1}$. Son frecuentes, pero rara vez constituyen una complicación y se resuelven con el tratamiento de la enfermedad. Los hallazgos más comunes son la leucopenia y linfocitosis relativa, se describen hasta en $28 \%$ de los pacientes. La pancitopenia ocurre en 5 a $20 \%$ de los pacientes, y puede ser secundaria a hemofagocitosis de causa multifactorial. Se han reportado casos aislados de rotura esplénica, coagulación intravascular diseminada (CID) y anemia hemolítica ${ }^{27,28}$.
El caso clínico que motivó esta comunicación, se presentó como un síndrome febril prolongado, de más de 30 días de evolución, cursó con hepato-esplenomegalia, manifestaciones cutáneas, artralgias, neutropenia y niveles bajos de PCR; algunos de estos elementos constituyeron factores de riesgo para desarrollar una forma focal, que se evidenció por el compromiso tibial derecho, detectado en el cintigrama óseo. Nuestro paciente no presentó signos inflamatorios ni impotencia funcional de la extremidad afectada, elementos descritos como criterios diagnósticos de la forma focal osteoarticular; es posible que la precocidad del estudio cintigráfico y las dosis de rifampicina que recibió antes de establecer el diagnóstico de brucelosis, hayan contribuido a un tratamiento parcial, impidiendo la aparición de esa sintomatología.

La neutropenia observada en este caso, que si bien, es atribuible al cuadro de brucelosis, pudo agravarse por el uso de ácido valproico, cuya administración fue discontinuada; cabe hacer notar, que esta manifestación fue relevante durante todo el curso de la enfermedad.

En nuestro paciente las bacteremias por $S$. mitis se relacionaron con neutropenia y extensa gingivoestomatitis. Este microorganismo es parte de la microbiota bucal, especialmente de los surcos gingivales y puede ocasionar infecciones graves en pacientes inmunocomprometidos. La presencia de S. mitis en hemocultivos, en conjunto con la dificultad para obtener los antecedentes epidemiológicos, lo que difiere de lo descrito en la literatura, dificultó el diagnóstico de brucelosis; luego del tratamiento de la infección estreptocóccica se logró el aislamiento, en los hemocultivos, de $B$. abortus, que confirmó el diagnóstico. En este caso clínico, también fueron relevantes las manifestaciones cutáneas, lo que es infrecuente, de acuerdo a lo descrito en la literatura médica.

La recaída de la brucelosis se produce en cerca de $10 \%$ de los casos y se asocia a algunos factores de riesgos como: sexo masculino, duración menor a 10 días de la enfermedad, trombocitopenia, bacteriemias y tratamiento inadecuado. Generalmente, ocurre en el primer año post- tratamiento ${ }^{29}$.

Diagnóstico etiológico. El diagnóstico de brucelosis se confirma con el aislamiento de Brucella sp en el mielocultivo o en hemocultivos, con una sensibilidad de 90 y 75\%, respectivamente. Con los métodos automatizados se ha observado un aumento de la sensibilidad, a alrededor de $95 \%$, pero dado las características de este microorganismo, ante la sospecha clínica, se debe avisar al laboratorio clínico, para prolongar el tiempo de incubación, a 20 días y subcultivar en forma ciega, si es necesario. Cabe señalar que a 
mayor tiempo de evolución de la enfermedad, disminuye la sensibilidad de los hemocultivos, no así, del cultivo de médula ósea ${ }^{30,31}$. También se puede recuperar de cultivos de orina y LCR, con una sensibilidad descrita de $39 \%$ y 35 a $50 \%$, respectivamente.

Las pruebas serológicas son de gran relevancia en el diagnóstico de la brucelosis. La mayoría de ellas detectan anticuerpos frente al lipopolisacárido (LPS) de la membrana externa, pero su principal limitante es su incapacidad para diferenciar infección activa y curada, ya que los anticuerpos persisten generalmente durante un período prolongado, tras la recuperación clínica.

Entre las pruebas serológicas, la más empleada es la aglutinación, en particular la sero-aglutinación de Wright-Huddleson y la aglutinación de rosa de bengala. La sero-aglutinación utiliza como antígeno a $B$. abortus muertas, detecta anticuerpos tipo IgM, contra B. abortus, B. suis, y B. melitensis.; Títulos de 1:160 o mayores indican infección activa. Se espera que los títulos desciendan a los 3 a 6 meses, con o sin curación de la enfermedad ${ }^{31}$. La aglutinación de rosa de bengala tiene buena sensibilidad y especificidad, con un alto grado de correlación con la sero-aglutinación de Wright-Huddleson; sin embargo, los títulos se mantienen elevados tras un tratamiento adecuado, por lo cual, no es un test válido para el seguimiento de estos pacientes y se le atribuye un rol de tamizaje ${ }^{31,32}$.

La prueba de Coombs es de gran utilidad para el diagnóstico de la brucelosis crónica, detecta la presencia de anticuerpos no aglutinantes, fundamentalmente del tipo IgG e IgA. El título obtenido, generalmente es más elevado que el de la seroaglutinación, puede mantenerse positivo de forma prolongada y con titulación elevada, incluso en pacientes con tratamiento adecuado y buena evolución clínica. Da falsos positivos por reacciones cruzadas con Vibrio cholerae, Francisella tularensis y Yersinia enterocolitica 09.

La aglutinación con 2-mercaptoetanol: es una modificación de la sero-aglutinación, se eliminan las moléculas de IgM perdiendo éstas su capacidad aglutinante, y permitiendo cuantificar la IgG. En la actualidad, este método prácticamente no se utiliza ${ }^{33-37}$.

La prueba de inmunocaptura-aglutinación, detecta IgG, títulos $>1 / 320$ se consideran significativos, tiene similar especificidad que la prueba de Coombs pero mayor sensibilidad ${ }^{38}$.

El enzimoinmunoanálisis (ELISA) determina $\mathrm{IgG}$, IgM o IgA, con buena sensibilidad y especificidad. La medición de anticuerpos IgM tiene una correlación muy alta con la sero-aglutinación, especialmente en los primeros meses de evolución; posteriormente hay un descenso en los títulos de ELISA-IgM, independientemente de la evolución clínica del paciente. Las
IgG e IgA tienen un componente como anticuerpos no aglutinantes, que son los que detecta la prueba de Coombs; debido a esto, la prueba ELISA IgA, y especialmente la determinación de ELISA IgG, muestran una alta correlación con la prueba de Coombs. El método de ELISA, puede detectar un aumento de la IgG y también de IgA en los pacientes que experimentan una recaída, pero no de IgM, lo cual, ayudaría al diagnóstico de esta situación clínica. La interpretación de la serología en los casos de evolución crónica es un problema que no está completamente resuelto ${ }^{36}$.

Para el diagnóstico de los casos de neurobrucelosis, el test de ELISA sería de mayor utilidad que la seroaglutinación ${ }^{39}$.

La persistencia serológica, aún con una evolución satisfactoria, es más frecuente en los pacientes que han presentado títulos muy elevados, al principio de la enfermedad, o en las formas focales de la infección. Cualquier título serológico debe compararse con los títulos previos; un incremento de los anticuerpos IgG o IgA, o la persistencia, debe evaluarse dentro del contexto clínico de cada paciente. Una variación de los títulos serológicos sólo se considera significativa, si es superior a una dilución.

La RPC en la fase aguda y en las recaídas tiene una sensibilidad de 94 a $100 \%$, con una especificidad de 98,5 a $100 \%$; por lo tanto, sería de gran utilidad para el diagnóstico, seguimiento y detección de recaídas, pero aún falta estandarización de la técnica y mayores estudios clínicos que permitan darle una adecuada interpretación, especialmente en las formas crónicas de la enfermedad ${ }^{40,41-46}$.

En nuestro caso, la reacción de Wright-Huddleson fue altamente positiva, lo que contribuyó junto al aislamiento de $B$. abortus, a confirmar el diagnóstico. Al año de seguimiento, tanto la reacción de WrightHuddleson, como la prueba de ELISA IgM arrojaron resultados negativos, persistiendo positiva la ELISA $\mathrm{IgG}$, en concordancia con lo descrito en la literatura, donde se describe que en las formas focales o que debutan con títulos muy elevados, puede permanecer positiva, aún con una evolución satisfactoria.

Actualmente en nuestro país, varios centros cuentan con la técnica de ELISA IgG e IgM. En el ISP se estudian las muestras de pacientes con sospecha clínica mediante sero-aglutinación de Wright- Huddleson. Títulos igual o mayores a $1 / 110$ se consideran significativos, se realiza determinación de $\operatorname{IgG}$ e $\operatorname{IgM}$ por técnica de ELISA y en casos especiales se efectúa $\mathrm{RPC}$, técnica actualmente en proceso de estandarización.

Tratamiento antimicrobiano. El tratamiento de la brucelosis debe considerar la localización intracelular 
del agente causal, lo que dificulta su erradicación, de tal forma, que debe ser asociado y prolongado, para reducir la aparición de recaídas.

Las tetraciclinas son los antimicrobianos más efectivos en el tratamiento de la brucelosis, pero sólo pueden utilizarse en niños a partir de los 7 años de edad. La combinación de doxiciclina durante 6 semanas con un aminoglucósido durante 2 semanas tiene una tasa de recaídas de 5\%. Si bien el aminoglucósido clásicamente utilizado ha sido estreptomicina, actualmente se recomienda indicar gentamicina en una dosis diaria, durante 7 a 14 días, ya que, tiene mayor actividad in vitro y menor toxicidad. Hay publicados estudios que muestran cómo el tratamiento con doxiciclina por 45 días y gentamicina por 7 días, mantiene un porcentaje de recaídas alrededor de 5 a $6 \%$. Una reducción del tratamiento con doxiciclina, desde 45 a 30 días, se ha relacionado con un aumento de las recaídas ${ }^{47-49}$.

La combinación oral de doxiciclina y rifampicina por 45 días constituye una buena alternativa, por su tolerancia y comodidad, pero se acompaña de un porcentaje de recaída más elevado, alrededor del 15\%, lo que es relevante, especialmente en las formas complicadas de la enfermedad ${ }^{50-53}$.

En niños de 7 años o menor edad se recomienda la asociación de cotrimoxazol y rifampicina por 6 semanas. Una alternativa a este esquema sería emplear rifampicina durante 45 días asociada a gentamicina por 7 días.

Ciprofloxacina asociada a doxiciclina o rifampicina, puede considerarse como terapia alternativa $a^{52-56}$.

El tratamiento de las formas localizadas de la enfermedad, si bien no difiere sustancialmente de las recomendaciones generales, se puede acompañar de un mayor porcentaje de recaídas, especialmente en las formas supuradas o en los casos de espondilitis, osteoartritis $u$ orquiepididimitis. En estos casos se recomienda prolongar el tratamiento con doxiciclina a 8 semanas. En las formas osteoarticulares se ha visto una disminución de las recaídas usando terapias triasociadas con doxiciclina, gentamicina y rifampicina. En los casos de endocarditis y meningitis, hay que considerar la terapia con doxiciclina y aminoglucósidos asociada a rifampicina, para optimizar la acción bactericida, prolongando el tratamiento a no menos de 8 semanas; no es infrecuente la necesidad de recambios valvulares ${ }^{57-59}$. En los casos de meningitis no está probada la utilidad de los corticosteroides ${ }^{60}$.

En nuestro caso, inicialmente, se optó por una terapia triasociada, completando un total de 6 semanas, en consideración a su tiempo de evolución y al compromiso óseo evidenciado a la cintigrafía ósea, los que constituían factores de riesgo para una recaída.

Las medidas de prevención son fundamentales para evitar esta zoonosis, es así, como el SAG, ha implementado un plan de erradicación de la brucelosis bovina, a través de la vacunación de los bovinos hembras con la cepa RB51. Con esta medida se ha logrado disminuir la prevalencia en el ganado bovino $\mathrm{a} \sim 2 \%$, lo que, sumado a la educación de la población, enseñando la importancia de ingerir productos lácteos pasteurizados, debiera tender a disminuir la transmisión de la infección al Hombre.

\section{Resumen}

Se comunica el caso de un escolar, que presenta un síndrome febril prolongado de 2 meses y medio de evolución, con hepatoesplenomegalia, manifestaciones cutáneas, hematológicas y óseas que, sumadas a antecedentes epidemiológicos sugerentes, permitieron diagnosticar un cuadro de brucelosis. El diagnóstico fue confirmado por serología y hemocultivos positivos a Brucella abortus. Se relata la evolución clínica, tratamiento y seguimiento del paciente, analizamos las formas clínicas de presentación de esta enfermedad, las dificultades en el diagnóstico y seguimiento, como los tratamientos recomendados en la actualidad.

\section{Referencias}

1.- Abuhammour W, Nashar K. Brucellosis. http//:www.eMedicine.com/ ped.topic293.htm (2002 Julio, 16).

2.- al-Eissa YA, al-Mofada SM. Congenital brucellosis. Pediatr Infect Dis J 1992; 11: 667-71.

3.- Olea M A. Zoonosis. Boletín de Vigilancia en Salud Pública de Chile. El VIGIA 2003. Número 19: 40

4.- al-Eissa Y A, Kambal A M, al-Nasser M N, al-Habib S A, al-Fawaz I M, al-Zamil F A.
Childhood brucellosis. A study of 102 cases. Pediatr Infect Dis J. 1990; 9: 74-9.

5.- Ariza J. Brucelosis: Aspectos actuales de principal interés. Servicio Enfermedades Infecciosos, CSU. de Bellvitge. Control calidad. www.SEIMC.ORG/control/Servi-Sero /Brumcli.htm. 2006 Enero, 23.

6.- Olea M A. Boletín de Vigilancia en Salud Pública de Chile. Zoonosis y enfermedades de transmisión vectorial. El VIGIA 2004. Número 21: 45.

7.- Young E J. An overview of human brucellosis. Clin Infect Dis 1995; 21 (2):
283-9.

8.- Colmenero J D, Requera J M, Martos F, Sanchez De Mora D, Delgado M, Causse M, et al. Complications associated with Brucella melitensis infection: A study of 530 cases. Medicine 1996; 75: 195-211.

9.- El Miedany Y M, El Gaafary M, Baddour M, Ahmed I. Osteoarticular brucellosis: Are we in need to revise our therapeutic policy? J Rheumatol 2003; 30: 2666-72.

10.- Bravo M, Colmenero J D, Alonso A. HLA-B39 allele confers susceptibility to osteoarticular complications in human 
brucellosis. J Rheumatol 2003; 30: 1051-3.

11.- Navarro-Martínez A; Solera J, Corredoira J, Martínez-Alfaro E, Atienzar M; Ariza J, Epididimo-orchitis due to Brucella mellitensis: a retrospective study of 59 patients. Clin Infect Dis 2001; 33: 2017-22.

12.- Khan M Y, Mah M W, Memish Z A. Brucellosis in a pregnant women. Clin Infect Dis 2001; 32: 1172-7.

13.- Catalan M J, Claveria E, López J C. Neurobrucellosis: A new clinical classification. Neurology 1999; 52 (Suppl 2); 12: 422 .

14.- González García H, Fernández Alonso J E, de Paz García M, Ramos Sánchez C, Aguirre Gervas B. Meningitis como primera y única manifestación de brucelosis. An Esp Pediatr 2000; 53: 280-2.

15.- Shakir R A, Al-Din A S, Araj G F, Lulu A R, Mousa A R, Saadah M A. Clinical categories of neurobrucellosis: a report on 19 cases. Brain 1987; 110: 213-23.

16.- Reguera J M, Alarcón A, Miralles Pachón J, Juarez C, Colmenero JD. Brucella endocarditis: clinical, diagnostic, and therapeutic approach. Eur J Clin Microbiol Infect Dis 2003; 22: 647-50.

17.- Berbari EF, Cockerill FR 3rd, Steckelberg JM. Infective endocarditis due to unusual or fastidious microorganism. Mayo Clinic Proc 1997; 72: 532-42.

18.- Fernández Delgado M, García Zambrana J, García Diez F, Cabezas Fernandez M L. Brucella acute abdomen mimicking apendicitis. Amer J Med 2000; 108: 599-600.

19.- Ariza J, Pigrau C, Canas C, Marron A, Martínez F, Almirante B, et al. Current understanding and management of chronic hepatosplenic suppurative brucellosis. Clin Infect Dis. 2001; 32: 1024-33.

20.- Akritidis N, Pappas G. Ascites caused by brucellosis: a report of two cases. Scand J Gastroenterol 2001; 36: 110-2.

21.- Cervantes F, Bruguera M, Carbonel Force L, Webb S. Liver disease in brucellosis: Clinical and pathological study of 40 cases. Postgrad Med J 1982; 58: 346-50.

22.- Pappas G, Bosilkovski M, Akritidis N, Mastora M, Krteva L, Tsianos E. Brucellosis and the respiratory system. Clin Infect Dis 2003; 37: e95- 9 .

23.- Sanford J P. Brucella pneumonia. Semin Respir Infect 1997; 12: 24-7.

24.- Milionis H, Christou L, Elisaf M. Cutaneous manifestations in Brucellosis case report and review of the literature. Infection 2000; 28: 124-6.

25.- Ariza J, Servitje O, Pallares R, Fernández Viladrich P, Rufi G, Peyri J, et al. Characteristic cutaneous lesions in patient with brucellosis. Arch Dermatol 1989; 125: 3803.
26.- Metin A, Akdenis H, Buzgan T, Delice I. Cutaneous findings encountered in Brucellosis and review of the literature. Int J Dermatol 2001: 40: 434-8.

27.- Young E J, Tarry A, Genta R M, Ayden N, Gotuzzo E. Thrombocytopenic purpura associated with brucellosis: report of 2 cases and literature review. Clin Infect Dis 2000; 31: 904-9.

28.- Pappas G, Kitsanou M, Christou L, Tsianos E. Immune thrombocytopenia attributed to brucellosis and other mechanisms of Brucella-induced thrombocytopenia. Am J Hematol 2004; 75: 139-41.

29.- Ariza J, Corredoira J, Pallares R. Characteristics of and risk factors relapse of brucellosis in humans. Clin Infect Dis 1995; 20: 1241-9.

30.- Gotuzzo E, Carrillo C, Guerra J, Llosa L. An evaluation of diagnostic methods brucellosisthe value of bone marrow culture. J Infect Dis 1986; 153:122-5.

31.- Ariza J, Pellicer T, Pallares R, Foz A, Gudiol F. Specific antibody prolife in human brucellosis. Clin Infect Dis 1992; 14: 131-40.

32.- Young E J. Serologic diagnosis of human brucellosis: Analysis of 214 cases by agglutination tests and review of the literature. Rev Infect Dis 1991; 13: 359-72.

33.- Casao M A, Smits H L, Navarro E, Solera J. Clinical utility of a dipstick assay in patients with brucellosis: correlation with the period of evolution of the disease. Clin Microbiol Infect 2003; 9: 301-5.

34.- Al Dahouk S, Tomaso H, Nockler K, Neubauer H, Frangoulidis D. Laboratory based diagnosis of brucellosis-a review of the literature. Part II: Serological tests for brucellosis. Clin Lab 2003; 49: 577-89.

35.- Montes I, Hernández P, Rodríguez-Mayo M, Muñoz J R. Agulla A. Evaluation of three commercially available blood culture systems for cultivation and detection of Brucella melitensis. Abstracts of the $37^{\text {th }}$ ICAAC. Toronto Canadá 1997. September 28October 1. Abstr D-115, pag: 103.

36.- Ortiz F M, Lopera E, Ceballos P, Merino R, Valle M, Gascón F. Brucelosis: Comparación de los tests serológicos de diagnóstico. Semergen. Rev Soc Esp de Medicina Rural y Generalista 1999; 25: 16-9.

37.- Almuneef M, Memish Z A. Prevalence of Brucella antibodies after acute brucellosis. J Chemother 2003; 15: 148-51.

38.- Orduña A, Almaraz A, Prado A, Gutiérrez P, García-Pascual A, Dueñas A, et al. Evaluation for an immunocapture-aglutination test for the serodiagnosis of human brucellosis. J Clin Microbiol 2000; 38: 4000-5.

39.- Araj G F, Lulu A R, Khateeb M I, Saadah M A, Shakir R A. ELISA versus routine tests in the diagnosis of patients with systemic and neurobrucellosis. APMIS 1988; 96: 171-6.

40.- Romero C, Gamazo C, Pardo M, López-Goñi I. Specific detection of Brucella DNA by PCR. J Clin Microbiol 1995; 33: 615-7.

41.- Baily G G, Krahn J B, Drasar B S, Stoker N G. Detection of Brucella melitensis and Brucella abortus by DNA by PCR amplification. J Trop Med Hyg 1992; 95: 271-5.

42.- Nimri LF. Diagnosis of recent and relapsed cases of human brucellosis by PCR assay. BMC Infect Dis 2003; 3: 5.

43.- Morata P, Queipo-Ortuno M I, Reguera J M, García-Ordonez M A, Pichardo C, Colmenero J D. Posttreatment follow-up of brucellosis by PCR assay. J Clin Microbiol 1999; 37: 4163-6.

44.- Matar G M, Khneisser I A, Abdelnoor A M. Rapid laboratory confirmation of human brucellosis by PCR analysis of a target sequence on the 31-kilodalton Brucella antigen DNA. J Clin Microbiol 1996; 34: 477-8.

45.- Probert W S, Schrader K N, Khuong N Y, Bystrom S L, Graves M H. Real-time multiplex PCR assay for detection of Brucella spp., B. abortus, and B. melitensis. J Clin Microbiol 2004; 42: 1290-3

46.- Queipo- Ortuno M I, Colmenero J D, Baeza G, Morata P. Comparison between Lightcycler real-time polymerase chain reaction (PCR) assay with serum and PCR enzyme-linked immunosorbent assay with whole blood samples for the diagnosis of human brucellosis. Clin Infect Dis 2005; 40: 260-4.

47.- Najwa A, Khuri-Bulos H, Daoud Saia M A. Treatment of childhood brucellosis, result of a prospective trial on 113 children. Pediatr Infect Dis J 1993; 12: 377-81.

48.- Lubani M M, Dudin K I, Sharda D C, Mana Ndhar D S, Araj G F, Hafez H A, et al. A multicenter therapeutic study of 1100 children with brucellosis. Pediatr Infect Dis J 1989; 8: 75-8.

49.- Malik G M. Early clinical response to different therapeutic regimens for human Brucellosis. Am J Trop Med Hyg 1998; 58: 190-1.

50.- Solera J, Martínez-Alfaro E, Espinosa A. Recognition and optimum treatment of brucellosis. Drugs 1997; 53: 245-56.

51.- Solera J, Espinosa A, Martinez-Alfaro E, Sánchez L, Geijo P, Navarro E, et al. Treatment of human brucellosis with doxycicline and gentamicin Antimicrob Agents Chemother 1997; 41: 80-4

52.- Pappas G, Seitaridis S, Akritidis N, Tsianos E. Treatment of brucella spondylitis: lessons from an impossible 
meta-analysis and initial report of efficacy of a fluoroquinolone-containing regimen. Int J Antimicrob Agents 2004; 24: 502-7.

53.- Agalar C. Usubutun S, Turkvilmaz R. Ciprofloxacin and rifampicin versus doxycycline and rifampicin in the treatment of brucellosis. Eur J Microbiol Infect Dis 1999; 535-8.

54.- Khuri-Bulos N A, Daoud A H, Azab S M. Treatment of childhood brucellosis results of a prospective trial on 113 children. Pediatr Infect Dis J 1993; 12: 377-81.

55.- Karabay O, Sencan I, Kayas D, Sahin I. Ofloxacin plus rifampicin versus doxycycline plus rifampicin in the treatment of brucellosis: a randomized clinical trial [ISRCTN11871179]. BMC Infect Dis 2004; 4: 18.

56.- López-Merino A, Contreras-Rodríguez A, Migranas-Ortiz R. Susceptibility of Mexican Brucella isolates to moxifloxacin,

ciprofloxacin and other antimicrobials use in the treatment of human brucellosis. Scand J Infect Dis 2004; 36: 636-8.

57. - Solera J, Beato J L, Martínez-Alfaro E, Segura J C, de Tomas E. Azithromycin and gentamicin therapy for the treatment of humans with brucellosis. Clin Infect Dis
2001; 32: 506-9.

58.- Cohen N, Golik A, Alon I, Zaidenstein R, Dishi V, Karpuch J, et al. Conservative treatment for Brucella endocarditis. Clin Cardiol 1997; 20: 291-4.

59.- Uddin M J, Sanyal S C, Mustafa A S, Mokaddas EM, Salama AL, Cherian G, et al. The role of aggressive medical therapy along with early surgical intervention in the cure of Brucella endocarditis. Ann Thorac Cardiovasc Surg 1998; 4: 209- 13.

60.- McLean D R, Russell N, Khan M Y. Neurobrucellosis: clinical and therapeutic features. Clin Infect Dis 1992; 15: 582-90. 